\title{
Pachastrissamine (jaspine B) and its stereoisomers inhibit sphingosine kinases and atypical protein kinase $\mathrm{C}$.
}

\section{$\operatorname{AUTHOR}(\mathrm{S})$ :}

Yoshimitsu, Yuji; Oishi, Shinya; Miyagaki, Jun; Inuki, Shinsuke; Ohno, Hiroaki; Fujii, Nobutaka

\section{CITATION:}

Yoshimitsu, Yuji ...[et al]. Pachastrissamine (jaspine B) and its stereoisomers inhibit sphingosine kinases and atypical protein kinase C.. Bioorganic \& medicinal chemistry 2011, 19(18): 5402-5408

\section{ISSUE DATE:}

2011-09-15

URL:

http://hdl.handle.net/2433/147238

\section{RIGHT:}

(c) 2011 Elsevier Ltd.; この論文は出版社版でありません。引用の際には 出版社版をご確認ご利用ください。; This is not the published version. Please cite only the published version. 
Pachastrissamine (Jaspine B) and its Stereoisomers Inhibit Sphingosine Kinases and Atypical Protein Kinase C

Yuji Yoshimitsu, Shinya Oishi*, Jun Miyagaki, Shinsuke Inuki, Hiroaki Ohno, and Nobutaka Fujii* Graduate School of Pharmaceutical Sciences, Kyoto University, Sakyo-ku, Kyoto 606-8501, Japan

\section{Corresponding Authors:}

Shinya Oishi, Ph.D. and Nobutaka Fujii, Ph.D.

Graduate School of Pharmaceutical Sciences

Kyoto University

Sakyo-ku, Kyoto, 606-8501, Japan

Tel: +81-75-753-4551; Fax: +81-75-753-4570,

E-mail (S.O.): soishi@pharm.kyoto-u.ac.jp; E-mail (N.F.): nfujii@pharm.kyoto-u.ac.jp 
Abstract: Sphingosine kinases (SphKs) are oncogenic enzymes that regulate the critical balance between ceramide and sphingosine-1-phosphate. Much effort has been dedicated to develop inhibitors against these enzymes. Naturally occurring pachastrissamine (jaspine B) and all its stereoisomers were prepared and evaluated for their inhibitory effects against SphKs. All eight stereoisomers exhibited moderate to potent inhibitory activity against SphK1 and SphK2. Inhibitory effects were profiled against protein kinase $\mathrm{C}(\mathrm{PKC})$ isoforms by in vitro experiments. Atypical PKCs ( $\mathrm{PKC} \zeta$ and $\mathrm{PKCl}$ ) were inhibited by several pachastrissamine stereoisomers. The improved activity over $N, N$-dimethylsphingosine suggests that the cyclic scaffold in pachastrissamines facilitates potential favorable interactions with SphKs and PKCs.

Keywords: jaspine B, pachastrissamine, protein kinase C, sphingosine kinase, sphingolipid

\section{Introduction}

Sphingolipid metabolites such as ceramide (Cer), sphingosine (Sph), and sphingosine-1phosphate (S1P) play important parts in diverse biological processes. ${ }^{1}$ It has been reported that Cer and Sph promote apoptosis and inhibit proliferation, whereas S1P mediates cell proliferation and angiogenesis. ${ }^{2,3}$ The binding of S1P to a family of five specific G protein-coupled receptors termed $\mathrm{S} 1 \mathrm{PR}_{1-5}$ controls various biological functions. S1P can also regulate intracellular processes, but molecular targets are not fully defined. ${ }^{4}$ Sphingosine kinases (SphKs), which catalyze the phosphorylation of Sph to form S1P are important lipid kinases. ${ }^{5} \mathrm{~S} 1 \mathrm{P}$ levels are mainly regulated by SphKs, S1P lyase, and S1P phosphatases (Figure 1). Hitherto, two distinct isoforms of SphKs, SphK1, and SphK2, have been reported. ${ }^{6,7} \mathrm{SphK} 1$ is overexpressed in various human tumors, ${ }^{8}$ thereby impairing the efficacy of chemotherapy. ${ }^{9}$ SphK1 inhibition by siRNA-mediated knockdown or pharmacologic inhibition induces apoptosis with elevation of the Cer/S1P ratio, ${ }^{9}$ and increases the effectiveness of docetaxel in prostate cancer cell lines. ${ }^{10}$ 
SphK2 is defferent in its amino terminus and central region from SphK1. These two enzymes have different kinetic properties and tissue expression, implying that they may have distinct physiological roles. Indeed, in contrast to pro-survival SphK1, the SphK2 induces apoptosis by cytochrome c release. ${ }^{11}$ Recent investigations revealed that a selective inhibitor of SphK2 attenuates experimental osteoarthritis. ${ }^{12}$ Accordingly, SphKs could be promising drug targets for cancer chemotherapy and inflammatory diseases. So far, a number of sphingosine kinase inhibitors have been reported. $^{13}$

Pachastrissamine, a naturally occurring anhydrophytosphingosine derivative, was isolated from the Okinawan marine sponge, Pachastrissa sp. (Figure 2). ${ }^{14}$ Pachastrissamine exhibits marked submicromolar cytotoxicity against several cancer cell lines. Delgado and co-workers reported the cytotoxicity of pachastrissamine diastereomers with a series of C-2 and C-3 stereochemistries on the tetrahydrofuran core, which were prepared via Sharpless asymmetric dihydroxylation. ${ }^{15}$ Rao and coworkers also revealed that pachastrissamine enantiomer is less cytotoxic than pachastrissamine. ${ }^{16}$ There has also been significant interest in the molecular mechanisms of cell death induced by pachastrissamine. Salma et al. revealed that pachastrissamine inhibits sphingomyelin synthase to increase the intracellular level of Cer, inducing apoptotic cell death by a caspase-dependent pathway. ${ }^{17}$ However, its activity against isolated sphingolipid metabolizing enzymes has yet to be investigated. In the present study, we investigated the inhibitory activities of eight pachastrissamine stereoisomers 1-8 against SphKs in vitro (Figure 2).

\section{Results and discussion}

\subsection{Synthesis of pachastrissamine stereoisomers}

Previously, we developed a stereoselective synthesis of four pachastrissamine diastereomers 1-4 with the $4 S$-configuration. ${ }^{18}$ This synthetic route divergently provides four pachastrissamine diastereomers from $S$-Garner's aldehyde as a sole chiral pool. We prepared the other enantiomeric stereoisomers 5-8 using this successful approach from $R$-Garner's aldehyde (Scheme 1). Briefly, $R$ - 
Garner's aldehyde was converted into $\mathbf{1 1}$ by treatment with a phosphonium ylide followed by dihydroxylation with $\mathrm{OsO}_{4}{ }^{19}$ The diol 11 was converted into the corresponding bis-tosylate 12 with $\mathrm{TsCl}, \mathrm{Et}_{3} \mathrm{~N}$ and $\mathrm{Me}_{3} \mathrm{~N} \cdot \mathrm{HCl}$. Treatment of 12 with $\mathrm{TsOH}$ successfully constructed the expected tetrahydrofuran ring. Cleavage of the tosyl group with $\mathrm{Mg}$ in $\mathrm{MeOH}$ gave the $(2 R, 3 R, 4 R)$-isomer 5 . Regioselective tosylation of the primary hydroxy group of the D-ribo-phytosphingosine derivative 14 prompted spontaneous cyclization to give the tetrahydrofuran, and removal of the Boc group with TFA provided the desired product, $\mathbf{6}^{20}$

The primary hydroxy group of $\mathbf{1 4}$ was protected with a TIPS group. Subsequent conversion of the resulting silyl ether to oxazolidinone using $\mathrm{MeC}(\mathrm{OMe})_{3}$ in the presence of a catalytic amount of $\mathrm{BF}_{3} \cdot \mathrm{OEt}_{2}$ afforded 17. Protection of the carbamate nitrogen of 17 with $\mathrm{Boc}_{2} \mathrm{O}$ and alcoholysis of the oxazolidinone successfully provided $\mathbf{1 8}$. Similar to the synthesis of $\mathbf{5}$, bis-tosylation, desilylation and TBAF-promoted tetrahydrofuran formation afforded the desired core scaffold that was successively deprotected with $\mathrm{Mg}$ and TFA to furnish 7.

The silyl ether of $\mathbf{1 8}$ was cleaved with TBAF in THF to give the triol 21. Selective monotosylation of the primary hydroxy group followed by base treatment afforded tetrahydrofuran 22. The Boc group was removed with TFA to give $\mathbf{8}$.

\subsection{Sphingosine kinase inhibition by pachastrissamine stereoisomers}

To evaluate the SphK inhibitory activity of pachastrissamines, in vitro SphK inhibition assays were undertaken for SphK1 and SphK2 based on the partitioning of Sph and S1P using the LabChip3000 system. $^{21} \mathrm{~N}, \mathrm{~N}$-dimethylsphingosine (DMS) was employed as a reference SphK inhibitor (Table 1). ${ }^{22}$ Interestingly, all of the pachastrissamine stereoisomers exhibited an inhibitory effect on both SphKs. Among the compounds tested, $(2 R, 3 S, 4 R)$-isomer 7 and $(2 S, 3 S, 4 R)$-isomer 8 exhibited most potent inhibitory activity upon SphK1 and SphK2, respectively, which are more potent than DMS. These results indicate that a primary hydroxy group in the substrate Sph, which is 
phosphorylated by SphKs, may not be essential for enzyme recognition. The stereochemistry of the accessory amino and hydroxyl groups on the tetrahydrofuran core has significant influence on SphK inhibitory potency. This apparently ambiguous recognition of stereochemistry resembles the potent SphK inhibitory effect by D- and L-threo-sphingosines. ${ }^{23-25}$ Inhibitory activity of 7 and $\mathbf{8}$ may be due to sphingosine-like conformation of hydroxy and amino groups. The hydrophobic tetradecyl moiety probably significantly contributes to binding to $\mathrm{SphK}$ by hydrophobic interactions, corresponding to known inhibitors with sphingosine-based structures. ${ }^{23-26}$ Whereas the cis-olefincontaining hydrocarbon is indispensable for SphK inhibition by B-5354c, ${ }^{27}$ the saturated aliphatic chain of pachastrissamines subserves effective SphK suppression.

\subsection{Protein kinase $\mathrm{C}(\mathrm{PKC})$ inhibition by pachastrissamine stereoisomers}

DMS was also reported to work as a protein kinase $\mathrm{C}$ (PKC) inhibitor. Hence, the bioactivity of pachastrissamine 1, and potent SphK inhibitors $\mathbf{7}$ and $\mathbf{8}$ were profiled against each PKC isoform (Figure 3). Although numerous studies on Sph itself and DMS were revealed, ${ }^{28,29}$ little is known about its isoform selectivity. The individual PKC isoform is involved in different cellular process, ${ }^{30}$ so the importance of the selectivity profiles of inhibitors is emphasized. For example, $\mathrm{PKC} \zeta$ has been implicated in epidermal growth factor (EGF)-stimulated chemotaxis of cancer cells, whereas $\mathrm{PKCl}$ is an oncogenic protein required for the transformed growth and tumorigenesis of human cancer cells. ${ }^{31}$ Pachastrissamines 1, 7 and $\mathbf{8}$ exerted complete inhibition of $\mathrm{PKC} \zeta$ and $\mathrm{PKC} \mathrm{r}$ at 10 $\mu \mathrm{M}$, whereas modest inhibition against the other PKCs was observed (see the Supplementary data). The inhibitory effects of pachastrissamine isomers at $3 \mu \mathrm{M}$ against $\mathrm{PKC} \zeta$ and $\mathrm{PKC \imath}$ were $\sim 50 \%$, which were more potent than the reference DMS (Figure 3). To our best knowledge, this is the first report on the Sph-based PKC inhibitors with selectivity for atypical PKC isozymes in vitro.

The catalytic domain (motifs required for ATP-substrate binding and catalysis) of PKC is highly conserved among three subfamilies: conventional PKCs (PKC $\alpha, \beta 1, \beta 2, \gamma)$, novel PKCs (PKC $\delta, \varepsilon$, 
$\theta, \eta)$, and atypical PKCs $(\mathrm{PKC} \zeta, \imath)$, whereas the structural features of the regulatory domain vary. ${ }^{32}$ Conventional PKCs and novel PKCs have a C1 domain that binds diacylglycerol (DAG) for kinase activation. In the in vitro assay system for the present study, conventional PKCs/novel PKCs were activated by the addition of DAG. The addition of DAG for conventional PKCs/novel PKCs may diminish the potential inhibitory effects by pachastrissamines. ${ }^{26,33}$ In contrast, atypical PKCs, including distinct nucleotide binding loop and ATP binding pocket, bind phosphatidylinositol 3,4,5trisphosphate $\left(\mathrm{PIP}_{3}\right)$ and $\mathrm{Cer}$ (not DAG) in the atypical $\mathrm{Cl}$ domain, whereas they lack a DAG binding site in the regulatory domain. Considering that sphingolipid Cer binds to the atypical $\mathrm{C} 1$ domain, ${ }^{34}$ PKC-isoform selectivity of pachastrissamines could be derived from the binding to the site in the domain. ${ }^{35}$

\section{Conclusions}

In conclusion, we identified pachastrissamine (jaspine B) as a novel SphK1 and SphK2 inhibitor. Several non-natural stereoisomers are more potent $\mathrm{SphK}$ inhibitors than the naturally occurring pachastrissamine. The distinct chiral tetrahydrofuran scaffold with accessory groups could facilitate favorable interactions with both enzymes. In addition, the inhibitory activities of these SphK inhibitors against atypical $\mathrm{PKCs}(\mathrm{PKC} \zeta, \mathrm{PKC} \imath)$ were revealed, suggesting that SphKs and PKCs represent alternative molecular targets of pachastrissamines to induce apoptotic process. As such, these pachastrissamine stereoisomers obtained by our unique divergent synthesis could be promising leads to design sphingolipid-based kinase inhibitors. Further optimization of these inhibitors (especially for the alkyl side-chains) and investigations to elucidate the biological impact of these inhibitors are underway.

\section{Experimental}

\subsection{Synthesis}


4.1.1. General Methods. ${ }^{1} \mathrm{H}$ NMR spectra were recorded using a JEOL AL-400 or a JEOL ECA500 spectrometer at 400 or $500 \mathrm{MHz}$ frequency, and chemical shifts are reported in $\delta(\mathrm{ppm})$ relative to TMS (in $\mathrm{CDCl}_{3}$ ) as internal standard. ${ }^{1} \mathrm{H}$ NMR spectra are tabulated as follows: chemical shift, multiplicity $(\mathrm{b}=$ broad, $\mathrm{s}=$ singlet, $\mathrm{d}=$ doublet, $\mathrm{t}=$ triplet, $\mathrm{q}=$ quartet, $\mathrm{br} \mathrm{s}=$ broad singlet, $\mathrm{m}=$ multiplet), number of protons, and coupling constant(s). All ${ }^{1} \mathrm{H}$ NMR spectra were in agreement with those of the enantiomers of our previous report. ${ }^{18}$ Optical rotations were measured with a JASCO P-1020 polarimeter. Exact mass (HRMS) spectra were recorded on a JMS-HX/HX 110A mass spectrometer. The purity of the compounds was determined by ${ }^{1} \mathrm{H}$ NMR and elemental analysis $(>95 \%)$.

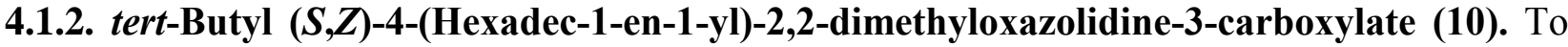
a stirred solution of $\mathrm{C}_{15} \mathrm{H}_{31} \mathrm{PPh}_{3} \mathrm{Br}(53.3 \mathrm{~g}, 96.3 \mathrm{mmol})$ in THF (350 mL) was added LHMDS (1.0 $\mathrm{M}$ in THF; $88.0 \mathrm{~mL}, 88.0 \mathrm{mmol})$ at $0{ }^{\circ} \mathrm{C}$, and the mixture was stirred for $0.5 \mathrm{~h}$ at room temperature. To the resulting dark red solution was added dropwise Garner's aldehyde 9 (9.60 g, $41.9 \mathrm{mmol})$ in THF $(70.0 \mathrm{~mL})$ at $-78^{\circ} \mathrm{C}$. The mixture was stirred for $30 \mathrm{~min}$ at this temperature and then $8 \mathrm{~h}$ at room temperature. The mixture was quenched by addition of saturated $\mathrm{NH}_{4} \mathrm{Cl}$ at $0{ }^{\circ} \mathrm{C}$, and concentrated under reduced pressure. The residue was extracted with $\mathrm{Et}_{2} \mathrm{O}$. The extract was washed with brine, and dried over $\mathrm{MgSO}_{4}$. The filtrate was concentrated under reduced pressure followed by rapid filtration through a short pad of silica gel with $n$-hexane-EtOAc (10:1) to give a crude mixture. Further purification by flash chromatography over silica gel with $n$-hexane-EtOAc (100:1 to $80: 1)$ gave $10(15.4 \mathrm{~g}, 87 \%)$ as a colorless oil; $[\alpha]^{25}-59.4\left(c 0.43, \mathrm{CHCl}_{3}\right) ;{ }^{1} \mathrm{H} \mathrm{NMR}(500 \mathrm{MHz}$, $\left.\mathrm{CDCl}_{3}\right) \delta 0.88(\mathrm{t}, J=6.9 \mathrm{~Hz}, 3 \mathrm{H}), 1.22-1.33(\mathrm{~m}, 24 \mathrm{H}), 1.36-1.62(\mathrm{~m}, 15 \mathrm{H}), 1.98-2.18(\mathrm{~m}, 2 \mathrm{H})$, $3.64(\mathrm{dd}, J=8.6,4.0 \mathrm{~Hz}, 1 \mathrm{H}), 4.05(\mathrm{dd}, J=8.6,6.3 \mathrm{~Hz}, 1 \mathrm{H}), 4.66(\mathrm{~m}, 1 \mathrm{H}), 5.35-5.54(\mathrm{~m}, 2 \mathrm{H})$; HRMS (FAB) calcd for $\mathrm{C}_{26} \mathrm{H}_{50} \mathrm{NO}_{3}\left(\mathrm{MH}^{+}\right)$424.3785, found 424.3784.

\subsection{3. tert-Butyl (R)-4-[(1R,2S)-1,2-Dihydroxyhexadecyl]-2,2-dimethyloxazolidine-3-} carboxylate (11). To the stirred solution of $10(6.7 \mathrm{~g}, 15.8 \mathrm{mmol})$ and $N$-methylmorpholine $N$-oxide 
$(2.8 \mathrm{~g}, 23.7 \mathrm{mmol})$ in $t$ - $\mathrm{BuOH}(40 \mathrm{~mL})$ and water $(40 \mathrm{~mL})$ was added $\mathrm{OsO}_{4}(2.5 \mathrm{w} / \mathrm{v} \%$ in $t$ - $\mathrm{BuOH}$, $8.0 \mathrm{~mL}, 0.791 \mathrm{mmol}$ ) at $0{ }^{\circ} \mathrm{C}$, and the mixture was stirred for $9.0 \mathrm{~h}$ at room temperature. The mixture was quenched by addition of saturated $\mathrm{Na}_{2} \mathrm{~S}_{2} \mathrm{O}_{3}$ at $0{ }^{\circ} \mathrm{C}$, and concentrated under reduced pressure. The residue was extracted with $\mathrm{Et}_{2} \mathrm{O}$ and washed with brine, and dried over $\mathrm{MgSO}_{4}$. The filtrate was concentrated under reduced pressure to give an oily residue, which was purified by flash chromatography over silica gel with $n$-hexane-EtOAc (5:1) to give 11 (4.5 g, 62\% yield) and its C3/ C4-stereoisomer (1.4g, 19\% yield) as white solids. Recrystallization from $n$-hexane-EtOAc gave pure 11 as colorless crystals; $\mathrm{mp} 55-56{ }^{\circ} \mathrm{C} ;[\alpha]^{25}{ }_{\mathrm{D}}+8.87\left(\mathrm{c} 1.02, \mathrm{CHCl}_{3}\right) ;{ }^{1} \mathrm{H}$ NMR $(500 \mathrm{MHz}$, $\left.\mathrm{CDCl}_{3}\right) \delta 0.88(\mathrm{t}, J=6.9 \mathrm{~Hz}, 3 \mathrm{H}), 1.19-1.33(\mathrm{~m}, 24 \mathrm{H}), 1.47-1.52(\mathrm{~m}, 15 \mathrm{H}), 1.58-1.63(\mathrm{~m}, 2 \mathrm{H})$, 3.14-3.32 (m, 2H), 3.53-3.67 (m, 2H), $4.00(\mathrm{~m}, 1 \mathrm{H}), 4.11-4.25(\mathrm{~m}, 2 \mathrm{H})$; Anal. Calcd for $\mathrm{C}_{26} \mathrm{H}_{51} \mathrm{NO}_{5}: \mathrm{C}, 68.23 ; \mathrm{H}, 11.23 ; \mathrm{N}, 3.06$. Found: C, 67.95; H, 11.38; N, 3.08.

\subsection{4. tert-Butyl (R)-4-[(1R,2S)-1,2-Bis(tosyloxy)hexadecyl]-2,2-dimethyloxazolidine-3-} carboxylate (12). To a stirred solution of $11(194 \mathrm{mg}, 0.424 \mathrm{mmol})$ in $\mathrm{CH}_{2} \mathrm{Cl}_{2}(850 \mu \mathrm{L})$ were added $\mathrm{Et}_{3} \mathrm{~N}(588 \mu \mathrm{L}, 4.24 \mathrm{mmol}), \mathrm{TsCl}(404 \mathrm{mg}, 2.12 \mathrm{mmol})$ and $\mathrm{Me}_{3} \mathrm{~N} \cdot \mathrm{HCl}(41 \mathrm{mg}, 0.424 \mathrm{mmol})$ at room temperature. After stirring for $1 \mathrm{~d}$ at this temperature, the mixture was quenched by addition of saturated $\mathrm{NH}_{4} \mathrm{Cl}$ at $0{ }^{\circ} \mathrm{C}$ and the whole was extracted with $\mathrm{CH}_{2} \mathrm{Cl}_{2}$. The extract was washed with saturated $\mathrm{NH}_{4} \mathrm{Cl}$ and brine, and dried over $\mathrm{MgSO}_{4}$. The filtrate was concentrated under reduced pressure to give an oily residue, which was purified by flash chromatography over silica gel with $n$ hexane-EtOAc (10:1 to $7: 1)$ to give 12 as a colorless oil $(285 \mathrm{mg}, 88 \%$ yield $) ;[\alpha]^{25}+23.9(c 0.68$, $\left.\mathrm{CHCl}_{3}\right) ;{ }^{1} \mathrm{H} \mathrm{NMR}\left(500 \mathrm{MHz}, \mathrm{CDCl}_{3}\right) \delta 0.88(\mathrm{t}, J=6.9 \mathrm{~Hz}, 3 \mathrm{H}), 1.08-1.33(\mathrm{~m}, 26 \mathrm{H}), 1.43-1.54(\mathrm{~m}$, 15H), $2.41(\mathrm{~s}, 3 \mathrm{H}), 2.43(\mathrm{~s}, 3 \mathrm{H}), 3.84(\mathrm{dd}, J=9.2,6.9 \mathrm{~Hz}, 1 \mathrm{H}), 3.92(\mathrm{dd}, J=9.2,2.9 \mathrm{~Hz}, 1 \mathrm{H}), 4.05$ $(\mathrm{m}, 1 \mathrm{H}), 4.63(\mathrm{~m}, 1 \mathrm{H}), 5.21(\mathrm{~m}, 1 \mathrm{H}), 7.26(\mathrm{~d}, J=8.0 \mathrm{~Hz}, 2 \mathrm{H}), 7.29(\mathrm{~d}, J=8.0 \mathrm{~Hz}, 2 \mathrm{H}), 7.73(\mathrm{~d}, J=$ $8.0 \mathrm{~Hz}, 2 \mathrm{H}), 7.78(\mathrm{~d}, J=8.0 \mathrm{~Hz}, 2 \mathrm{H})$; HRMS (FAB) calcd for $\mathrm{C}_{40} \mathrm{H}_{64} \mathrm{NO}_{9} \mathrm{~S}_{2}\left(\mathrm{MH}^{+}\right) 766.4017$, found 766.4015 . 


\subsection{5. (2R,3R,4R)-4-Amino-2-tetradecyltetrahydrofuran-3-yl 4-Methylbenzenesulfonate (13).}

To a stirred solution of $12(262 \mathrm{mg}, 0.342 \mathrm{mmol})$ in $\mathrm{MeOH}(11 \mathrm{~mL})$ was added $\mathrm{TsOH} \cdot \mathrm{H}_{2} \mathrm{O}(65 \mathrm{mg}$, $0.342 \mathrm{mmol}$ ) at $70{ }^{\circ} \mathrm{C}$. After stirring for $8 \mathrm{~h}$ at this temperature, the mixture was concentrated under reduced pressure to give an oily residue, which was purified by flash chromatography over silica gel with $\mathrm{CHCl}_{3}-\mathrm{MeOH}-28 \% \mathrm{NH}_{4} \mathrm{OH}(95: 4: 1)$ to give 13 as a white solid (140 mg, 90\% yield); mp 65$66{ }^{\circ} \mathrm{C} ;[\alpha]^{25}{ }_{\mathrm{D}}-18.6\left(c 0.28, \mathrm{CHCl}_{3}\right) ;{ }^{1} \mathrm{H} \mathrm{NMR}\left(500 \mathrm{MHz}, \mathrm{CDCl}_{3}\right) \delta 0.88(\mathrm{t}, J=6.9 \mathrm{~Hz}, 3 \mathrm{H}), 1.02-$ $1.32(\mathrm{~m}, 24 \mathrm{H}), 1.39-1.63(\mathrm{~m}, 4 \mathrm{H}), 2.46(\mathrm{~s}, 3 \mathrm{H}), 3.43(\mathrm{dd}, J=8.6,8.6 \mathrm{~Hz}, 1 \mathrm{H}), 3.72(\mathrm{~m}, 1 \mathrm{H}), 3.88$ (ddd, $J=4.6,4.6,4.0 \mathrm{~Hz}, 1 \mathrm{H}), 3.99$ (dd, $J=8.6,8.6 \mathrm{~Hz}, 1 \mathrm{H}), 4.85(\mathrm{dd}, J=4.6,4.6 \mathrm{~Hz}, 1 \mathrm{H}), 7.36(\mathrm{~d}$, $J=8.0 \mathrm{~Hz}, 2 \mathrm{H}), 7.83(\mathrm{~d}, J=8.0 \mathrm{~Hz}, 2 \mathrm{H})$; HRMS (FAB) calcd for $\mathrm{C}_{25} \mathrm{H}_{44} \mathrm{NO}_{4} \mathrm{~S}\left(\mathrm{MH}^{+}\right) 454.2986$, found 454.2993 .

4.1.6. (2R,3R,4R)-4-Amino-2-tetradecyltetrahydrofuran-3-ol (5). To a stirred mixture of 13 (23 mg, 0.0551mmol) in $\mathrm{MeOH}(1.1 \mathrm{~mL})$ was added $\mathrm{Mg}(13 \mathrm{mg}, 0.0551 \mathrm{mmol}$ ) at room temperature. After stirring for $1.5 \mathrm{~h}$ at this temperature, silica gel was added to the solution and the mixture was concentrated under reduced pressure. The residue was purified by flash chromatography over silica gel with $\mathrm{CHCl}_{3}-\mathrm{MeOH}-28 \% \mathrm{NH}_{4} \mathrm{OH}(95: 4: 1)$ to give $\mathbf{5}$ as a white solid (13 mg, 79\% yield); mp 95-96 ${ }^{\circ} \mathrm{C} ;[\alpha]^{25}{ }_{\mathrm{D}}-9.61\left(c 0.61, \mathrm{CHCl}_{3}\right) ;{ }^{1} \mathrm{H}$ NMR $\left(500 \mathrm{MHz}, \mathrm{CDCl}_{3}\right) \delta$ $0.88(\mathrm{t}, J=6.9 \mathrm{~Hz}, 3 \mathrm{H}), 1.20-1.49(\mathrm{~m}, 24 \mathrm{H}), 1.49-1.59(\mathrm{br} \mathrm{s}, 2 \mathrm{H}), 1.60-1.70(\mathrm{~m}, 2 \mathrm{H}), 3.52(\mathrm{dd}, J=$ 8.5, 7.1 Hz, 1H), $3.66(\mathrm{~m}, 1 \mathrm{H}), 3.73(\mathrm{ddd}, J=7.1,7.1,3.4 \mathrm{~Hz}, 1 \mathrm{H}), 3.87(\mathrm{dd}, J=4.6,3.4 \mathrm{~Hz}, 1 \mathrm{H})$, $3.92(\mathrm{dd}, J=8.5,7.3 \mathrm{~Hz}, 1 \mathrm{H})$. Anal. Calcd for $\mathrm{C}_{18} \mathrm{H}_{37} \mathrm{NO}_{2}: \mathrm{C}, 72.19 ; \mathrm{H}, 12.45 ; \mathrm{N}, 4.68$. Found: C, $72.10 ; \mathrm{H}, 12.63 ; \mathrm{N}, 4.65$.

4.1.7. tert-Butyl $[(2 R, 3 R, 4 S)-1,3,4-t$ trihydroxyoctadecan-2-yl)]carbamate (14). To a stirred solution of $11(2.42 \mathrm{~g}, 5.29 \mathrm{mmol})$ in $\mathrm{MeOH}(176 \mathrm{~mL})$ was added $\mathrm{TsOH} \cdot \mathrm{H}_{2} \mathrm{O}(101 \mathrm{mg}, 0.529$ mmol) at $0{ }^{\circ} \mathrm{C}$, and the mixture was stirred for $10 \mathrm{~h}$ at room temperature. The mixture was quenched by addition of $\mathrm{Et}_{3} \mathrm{~N}$ at $0{ }^{\circ} \mathrm{C}$ and concentrated under reduced pressure, followed by flash chromatography over silica gel with $n$-hexane-EtOAc (1:1) to give $\mathbf{1 4}$ as a white solid (1.93 g, 87\% 
yield).; mp $85-86{ }^{\circ} \mathrm{C} ;[\alpha]^{25}-6.61\left(c 1.61, \mathrm{CHCl}_{3}\right) ;{ }^{1} \mathrm{H}$ NMR $\left(500 \mathrm{MHz}, \mathrm{CDCl}_{3}\right) \delta 0.88(\mathrm{t}, J=6.9$ Hz, 3H), 1.21-1.39 (m, 24H), 1.45 (s, 9H), 1.47-1.55 (m, 2H), 2.42 (d, J=4.0 Hz, 1H), 2.98 (m, 1H), $3.29(\mathrm{~d}, J=6.9 \mathrm{~Hz}, 1 \mathrm{H}), 3.62(\mathrm{~m}, 1 \mathrm{H}), 3.68(\mathrm{~m}, 1 \mathrm{H}), 3.77(\mathrm{~m}, 1 \mathrm{H}), 3.85(\mathrm{~m}, 1 \mathrm{H}), 3.92(\mathrm{~m}, 1 \mathrm{H})$, $5.30(\mathrm{~m}, 1 \mathrm{H})$; HRMS (FAB) calcd for $\mathrm{C}_{23} \mathrm{H}_{48} \mathrm{NO}_{5}\left(\mathrm{MH}^{+}\right)$418.3527, found 418.3533 .

\subsection{8. tert-Butyl $[(3 R, 4 R, 5 S)-4-H y d r o x y-5$-tetradecyltetrahydrofuran-3-yl]carbamate (15).}

To a stirred mixture of $14(90 \mathrm{mg}, 0.216 \mathrm{mmol})$ and $\mathrm{Et}_{3} \mathrm{~N}(108 \mu \mathrm{L}, 0.778 \mathrm{mmol})$ in $\mathrm{CH}_{2} \mathrm{Cl}_{2}(7.2 \mathrm{~mL})$ were added $\mathrm{TsCl}(74 \mathrm{mg}, 0.389 \mathrm{mmol})$ and DMAP $(2.4 \mathrm{mg}, 0.0214 \mathrm{mmol})$ at $0{ }^{\circ} \mathrm{C}$, and the mixture was stirred for $18 \mathrm{~h}$ at room temperature. The mixture was quenched by addition of saturated $\mathrm{NH}_{4} \mathrm{Cl}$ at $0{ }^{\circ} \mathrm{C}$, and the whole was extracted with $\mathrm{CH}_{2} \mathrm{Cl}_{2}$. The extract was washed with brine, and dried over $\mathrm{MgSO}_{4}$. The filtrate was concentrated under reduced pressure to give an oily residue, which was purified by flash chromatography over silica gel with $n$-hexane-EtOAc (5:1 to 3:1) followed by recrystallization from $n$-hexane-EtOAc to give $\mathbf{1 5}$ (76 mg, 88\% yield) as colorless crystals.; mp 80$81{ }^{\circ} \mathrm{C} ;[\alpha]^{25}{ }_{\mathrm{D}}-7.76\left(c 0.29, \mathrm{CHCl}_{3}\right) ;{ }^{1} \mathrm{H} \mathrm{NMR}\left(500 \mathrm{MHz}, \mathrm{CDCl}_{3}\right) \delta 0.88(\mathrm{t}, J=6.9 \mathrm{~Hz}, 3 \mathrm{H}), 1.22-$ $1.34(\mathrm{~m}, 24 \mathrm{H}), 1.46(\mathrm{~s}, 9 \mathrm{H}), 1.52-1.57(\mathrm{~m}, 2 \mathrm{H}), 2.10(\mathrm{~m}, 1 \mathrm{H}), 3.51(\mathrm{~m}, 1 \mathrm{H}), 3.71(\mathrm{~m}, 1 \mathrm{H}), 3.94(\mathrm{~m}$, 1H), 4.11-4.17 (m, 2H), 4.95 (m, 1H); HRMS (FAB) calcd for $\mathrm{C}_{23} \mathrm{H}_{46} \mathrm{NO}_{4}\left(\mathrm{MH}^{+}\right)$400.3421, found 400.3413.

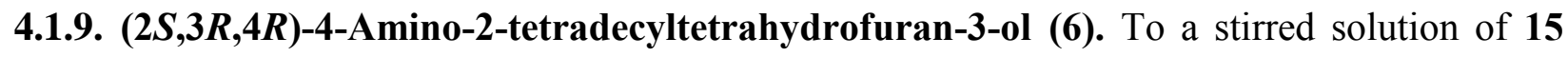
(45 mg, $0.113 \mathrm{mmol})$ in $\mathrm{CH}_{2} \mathrm{Cl}_{2}(800 \mu \mathrm{L})$ was added TFA $(800 \mu \mathrm{L})$ at $0{ }^{\circ} \mathrm{C}$, and the mixture was stirred for $30 \mathrm{~min}$ at room temperature. The mixture was concentrated under reduced pressure to give an oily residue, which was purified by flash chromatography over silica gel with $\mathrm{CHCl}_{3}-$ MeOH-28\% $\mathrm{NH}_{4} \mathrm{OH}(95: 4: 1)$ followed by recrystallization from $n$-hexane-EtOAc to give $\mathbf{6}$ as colorless crystals $(31 \mathrm{mg}, 92 \%$ yield $) ; \mathrm{mp} 104-105{ }^{\circ} \mathrm{C} ;[\alpha]^{25} \mathrm{D}-8.78\left(c 0.75, \mathrm{CHCl}_{3}\right) ;{ }^{1} \mathrm{H}$ NMR $(500$ $\left.\mathrm{MHz}, \mathrm{CDCl}_{3}\right) \delta 0.88(\mathrm{t}, J=6.9 \mathrm{~Hz}, 3 \mathrm{H}), 1.19-1.34(\mathrm{~m}, 24 \mathrm{H}), 1.34-2.37(\mathrm{~m}, 5 \mathrm{H}), 3.40(\mathrm{dd}, J=8.6$, $6.9 \mathrm{~Hz}, 1 \mathrm{H}), 3.46(\mathrm{~m}, 1 \mathrm{H}), 3.57-3.66(\mathrm{~m}, 2 \mathrm{H}), 4.13(\mathrm{dd}, J=8.6,6.3 \mathrm{~Hz}, 1 \mathrm{H})$. Anal. Calcd for $\mathrm{C}_{18} \mathrm{H}_{37} \mathrm{NO}_{2}$ : C, 71.12; H, 12.43; N, 4.61. Found: C, 71.39; H, 12.39; N, 4.59. 


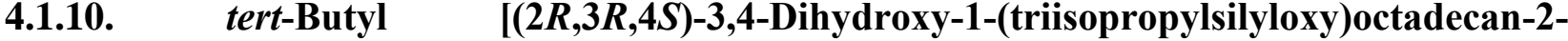

yl]carbamate (16). To a stirred solution of $14(1.74 \mathrm{~g}, 4.17 \mathrm{mmol})$ in DMF (42 $\mathrm{mL})$ were added imidazole $(1.14 \mathrm{~g}, 16.7 \mathrm{mmol})$ and $\operatorname{TIPSCl}(3.53 \mathrm{~mL}, 16.7 \mathrm{mmol})$ at $0{ }^{\circ} \mathrm{C}$, and the mixture was stirred for $1 \mathrm{~h}$ at room temperature. The mixture was quenched by addition of $\mathrm{MeOH}$ at $0{ }^{\circ} \mathrm{C}$, and concentrated under reduced pressure. The residue was diluted with $\mathrm{CH}_{2} \mathrm{Cl}_{2}$, washed with saturated $\mathrm{NH}_{4} \mathrm{Cl}$ and brine, and dried over $\mathrm{MgSO}_{4}$. The filtrate was concentrated under reduced pressure to give an oily residue, which was purified by flash chromatography over silica gel with $n$-hexaneEtOAc (8:1) to give 16 as a colorless oil $(2.15 \mathrm{~g}, 90 \%$ yield $) ;[\alpha]^{25}-23.5\left(c 0.25, \mathrm{CHCl}_{3}\right) ;{ }^{1} \mathrm{H}$ NMR $\left(500 \mathrm{MHz}, \mathrm{CDCl}_{3}\right) \delta 0.88(\mathrm{t}, J=6.9 \mathrm{~Hz}, 3 \mathrm{H}), 1.04-1.09(\mathrm{~m}, 18 \mathrm{H}), 1.10-1.18(\mathrm{~m}, 2 \mathrm{H}), 1.18-1.38(\mathrm{~m}$, 24H), 1.44 (s, 9H), 1.47-1.75 (m, 3H), $2.55(\mathrm{~d}, J=5.7 \mathrm{~Hz}, 1 \mathrm{H}), 3.24(\mathrm{~m}, 1 \mathrm{H}), 3.58(\mathrm{~m}, 1 \mathrm{H}), 3.63$ (m, 1H), $3.86(\mathrm{~m}, 1 \mathrm{H}), 3.89(\mathrm{~m}, 1 \mathrm{H}), 4.05(\mathrm{~m}, 1 \mathrm{H}), 5.24(\mathrm{~d}, J=8.0 \mathrm{~Hz}, 1 \mathrm{H})$; HRMS (FAB) calcd for $\mathrm{C}_{32} \mathrm{H}_{68} \mathrm{NO}_{5} \mathrm{Si}\left(\mathrm{MH}^{+}\right)$574.4861, found 574.4855.

\subsubsection{1. (S)-1-\{(4R,5S)-2-Oxo-4-[(triisopropylsilyloxy)methyl]oxazolidin-5-yl $\}$ pentadecyl}

Acetate (17). To a stirred solution of $16(1.56 \mathrm{~g}, 2.72 \mathrm{mmol})$ in $\mathrm{CH}_{2} \mathrm{Cl}_{2}(270 \mathrm{~mL})$ were added $\mathrm{MeC}(\mathrm{OMe})_{3}(2.0 \mathrm{~mL}, 16.3 \mathrm{mmol})$ and $\mathrm{BF}_{3} \cdot \mathrm{OEt}_{2}(67 \mu \mathrm{L}, 0.544 \mathrm{mmol})$ at $0{ }^{\circ} \mathrm{C}$, and the mixture was stirred for $1.5 \mathrm{~h}$ at room temperature. The mixture was quenched by addition of $\mathrm{MeOH}$ at $0{ }^{\circ} \mathrm{C}$, and concentrated under reduced pressure to give an oily residue, which was purified by flash chromatography over silica gel with $n$-hexane-EtOAc (4:1) to give $\mathbf{1 7}$ as a colorless oil (1.28 g, $87 \%$ yield $) ;[\alpha]^{25}{ }_{\mathrm{D}}+25.5\left(c 0.66, \mathrm{CHCl}_{3}\right) ;{ }^{1} \mathrm{H} \mathrm{NMR}\left(500 \mathrm{MHz}, \mathrm{CDCl}_{3}\right) \delta 0.88(\mathrm{t}, J=6.9 \mathrm{~Hz}, 3 \mathrm{H})$, $1.03-1.16(\mathrm{~d}, J=5.7 \mathrm{~Hz}, 18 \mathrm{H}), 1.08-1.14(\mathrm{~m}, 3 \mathrm{H}), 1.22-1.37(\mathrm{~m}, 24 \mathrm{H}), 1.63-1.75(\mathrm{~m}, 2 \mathrm{H}), 2.10(\mathrm{~s}$, 3H), 3.61-3.63 (m, 1H), 3.67-3.73 (m, 2H), $4.41(\mathrm{dd}, J=4.6,3.4 \mathrm{~Hz}, 1 \mathrm{H}), 5.00$ (ddd, $J=6.9,6.9$, 3.4 Hz, 1H), $5.28(\mathrm{~m}, 1 \mathrm{H})$; HRMS (FAB) calcd for $\mathrm{C}_{30} \mathrm{H}_{60} \mathrm{NO}_{5} \mathrm{Si}\left(\mathrm{MH}^{+}\right)$542.4235, found 542.4240.

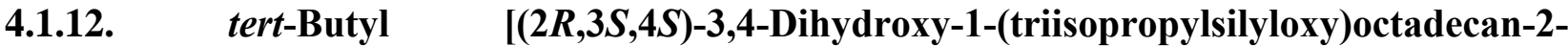

yl]carbamate (18). To a stirred solution of $17(760 \mathrm{mg}, 1.40 \mathrm{mmol})$ in THF (14 mL) were added $\mathrm{Et}_{3} \mathrm{~N}(194 \mu \mathrm{L}, 1.40 \mathrm{mmol}), \mathrm{Boc}_{2} \mathrm{O}(428 \mathrm{mg}, 1.96 \mathrm{mmol})$, and DMAP (343 mg, $\left.2.81 \mathrm{mmol}\right)$ at $0{ }^{\circ} \mathrm{C}$, 
and the mixture was stirred $2 \mathrm{~h}$ at room temperature. The mixture was quenched by addition of saturated $\mathrm{NH}_{4} \mathrm{Cl}$ at $0{ }^{\circ} \mathrm{C}$. The mixture was concentrated under reduced pressure, and the residue was extracted with $\mathrm{Et}_{2} \mathrm{O}$. The extract was washed with brine, and dried over $\mathrm{MgSO}_{4}$. The filtrate was concentrated under reduced pressure to give an oily residue, which was dissolved in $\mathrm{MeOH}$ (7.0 $\mathrm{mL})$. NaOMe $(1.13 \mathrm{~g}, 21.0 \mathrm{mmol})$ was added to this solution under stirring at $0{ }^{\circ} \mathrm{C}$, and the mixture was stirred for $10 \mathrm{~min}$ at room temperature. The mixture was quenched by addition of saturated $\mathrm{NH}_{4} \mathrm{Cl}$, and concentrated under reduced pressure. The residue was extracted with EtOAc, washed with brine, and dried over $\mathrm{MgSO}_{4}$. The filtrate was concentrated under reduced pressure to give an oily residue, which was purified by flash chromatography over silica gel with $n$-hexane-EtOAc (4:1) to give 18 as a colorless oil (562 mg, 70\% yield); $[\alpha]^{25}-20.6\left(c 3.21, \mathrm{CHCl}_{3}\right) ;{ }^{1} \mathrm{H}$ NMR (500 $\left.\mathrm{MHz}, \mathrm{CDCl}_{3}\right) \delta 0.88(\mathrm{t}, J=6.9 \mathrm{~Hz}, 3 \mathrm{H}), 1.07(\mathrm{~d}, J=5.7 \mathrm{~Hz}, 18 \mathrm{H}), 1.08-1.14(\mathrm{~m}, 3 \mathrm{H}), 1.14-1.42$ (m, 24H), $1.44(\mathrm{~s}, 9 \mathrm{H}), 1.45-1.61(\mathrm{~m}, 2 \mathrm{H}), 2.55(\mathrm{~m}, 1 \mathrm{H}), 3.46(\mathrm{~m}, 1 \mathrm{H}), 3.60(\mathrm{~m}, 1 \mathrm{H}), 3.66-3.79(\mathrm{~m}$, 2H), 3.79-3.99 (m, 2H), $5.15(\mathrm{~d}, J=8.0 \mathrm{~Hz}, 1 \mathrm{H})$; HRMS (FAB) calcd for $\mathrm{C}_{32} \mathrm{H}_{68} \mathrm{NO}_{5} \mathrm{Si}\left(\mathrm{MH}^{+}\right)$ 574.4861, found 574.4858 .

\subsubsection{3. $(2 R, 3 S, 4 S)-2-[($ tert-Butoxycarbonyl)amino]-1-(triisopropylsilyloxy)octadecane-3,4-} diyl Bis(4-methylbenzenesulfonate) (19). To a stirred solution of 18 (255 mg, $0.444 \mathrm{mmol})$ in $\mathrm{CH}_{2} \mathrm{Cl}_{2}(1.0 \mathrm{~mL})$ were added $\mathrm{Et}_{3} \mathrm{~N}(613 \mu \mathrm{L}, 4.44 \mathrm{mmol}), \mathrm{TsCl}(423 \mathrm{mg}, 2.22 \mathrm{mmol})$, and $\mathrm{Me}{ }_{3} \mathrm{~N} \cdot \mathrm{HCl}$ (42 mg, $0.444 \mathrm{mmol}$ ) at room temperature, and the mixture was stirred $4 \mathrm{~h}$ at room temperature. The mixture was quenched by addition of saturated $\mathrm{NH}_{4} \mathrm{Cl}$ at $0{ }^{\circ} \mathrm{C}$, and the whole was extracted with $\mathrm{CH}_{2} \mathrm{Cl}_{2}$, dried over $\mathrm{MgSO}_{4}$. The filtrate was concentrated under reduced pressure to give an oily residue, which was purified by flash chromatography over silica gel with $n$-hexane-EtOAc (10:1) to give 19 as a colorless oil (373 mg, 95\% yield); $[\alpha]^{25}{ }_{\mathrm{D}}-18.8\left(c 0.95, \mathrm{CHCl}_{3}\right) ;{ }^{1} \mathrm{H} \mathrm{NMR}(400 \mathrm{MHz}$, $\left.\mathrm{CDCl}_{3}\right) \delta 0.88(\mathrm{t}, J=6.9 \mathrm{~Hz}, 3 \mathrm{H}), 0.91-1.11(\mathrm{~m}, 26 \mathrm{H}), 1.11-1.36(\mathrm{~m}, 18 \mathrm{H}), 1.41(\mathrm{~s}, 9 \mathrm{H}), 1.54(\mathrm{~m}$, 3H), $2.44(\mathrm{~s}, 3 \mathrm{H}), 2.45(\mathrm{~s}, 3 \mathrm{H}), 3.46(\mathrm{dd}, J=10.3,6.3 \mathrm{~Hz}, 1 \mathrm{H}), 3.56(\mathrm{dd}, J=10.3,4.6 \mathrm{~Hz}, 1 \mathrm{H}), 4.01$ (m, 1H), $4.65(\mathrm{~m}, 1 \mathrm{H}), 4.79$ (d, $J=9.7 \mathrm{~Hz}, 1 \mathrm{H}), 5.03(\mathrm{dd}, J=4.6,3.4 \mathrm{~Hz}, 1 \mathrm{H}), 7.31(\mathrm{~d}, J=8.3 \mathrm{~Hz}$, 
2H), 7.34 (d, $J=8.3 \mathrm{~Hz}, 2 \mathrm{H}), 7.76(\mathrm{~d}, J=8.3 \mathrm{~Hz}, 2 \mathrm{H}), 7.85$ (d, $J=8.3 \mathrm{~Hz}, 2 \mathrm{H})$; HRMS (FAB) calcd for $\mathrm{C}_{46} \mathrm{H}_{79} \mathrm{NNaO}_{9} \mathrm{~S}_{2} \mathrm{Si}\left(\mathrm{MNa}^{+}\right)$904.4863, found 904.4863.

\subsubsection{4. (2R,3S,4R)-4-[(tert-Butoxycarbonyl)amino]-2-tetradecyltetrahydrofuran-3-yl 4-}

Methylbenzenesulfonate (20). To a stirred solution of 19 (172 mg, $0.195 \mathrm{mmol})$ in THF (3.9 mL) was added TBAF $(1.0 \mathrm{M}$ in THF; $390 \mu \mathrm{L}, 0.390 \mathrm{mmol})$ at $0{ }^{\circ} \mathrm{C}$, and the mixture was stirred for $2 \mathrm{~h}$ at room temperature. The mixture was quenched by addition of saturated $\mathrm{NH}_{4} \mathrm{Cl}$ at $0{ }^{\circ} \mathrm{C}$, and concentrated under reduced pressure. The residue was extracted with $\mathrm{Et}_{2} \mathrm{O}$, and dried over $\mathrm{MgSO}_{4}$. The filtrate was concentrated under reduced pressure to give an oily residue, which was purified by flash chromatography over silica gel with $n$-hexane-EtOAc (7:1) to give $\mathbf{2 0}$ as a colorless oil (71 mg, $65 \%$ yield $) ;[\alpha]^{25}{ }_{\mathrm{D}}+1.48\left(c 0.056, \mathrm{CHCl}_{3}\right) ;{ }^{1} \mathrm{H}$ NMR $\left(500 \mathrm{MHz}, \mathrm{CDCl}_{3}\right) \delta 0.88(\mathrm{t}, J=6.9 \mathrm{~Hz}, 3 \mathrm{H})$, 1.10-1.36 (m, $26 \mathrm{H}), 1.43$ (s, 9H), 2.45 (s, 3H), 3.73 (dd, $J=9.7,2.9 \mathrm{~Hz}, 1 \mathrm{H}), 3.78$ (dd, $J=9.7,5.2$ Hz, 1H), $3.93(\mathrm{~m}, 1 \mathrm{H}), 4.07(\mathrm{~m}, 1 \mathrm{H}), 4.43(\mathrm{~m}, 1 \mathrm{H}), 4.74(\mathrm{~m}, 1 \mathrm{H}), 7.53(\mathrm{~d}, J=8.0 \mathrm{~Hz}, 2 \mathrm{H}), 7.83(\mathrm{~d}$, $J=8.0 \mathrm{~Hz}, 2 \mathrm{H})$; HRMS (FAB) calcd for $\mathrm{C}_{30} \mathrm{H}_{50} \mathrm{NO}_{6} \mathrm{~S}\left([\mathrm{M}-\mathrm{H}]^{-}\right)$552.3364, found 552.3370.

4.1.15. (2R,3S,4R)-4-Amino-2-tetradecyltetrahydrofuran-3-ol (7). To a stirred solution of 20 (48 mg, $0.087 \mathrm{mmol})$ in $\mathrm{MeOH}(2.9 \mathrm{~mL})$ was added $\mathrm{Mg}(21 \mathrm{mg}, 0.87 \mathrm{mmol})$ at room temperature, and the mixture was stirred for $45 \mathrm{~min}$ at this temperature. The mixture was concentrated under reduced pressure, and the residue was diluted with EtOAc, washed with $\mathrm{H}_{2} \mathrm{O}$, and dried over $\mathrm{MgSO}_{4}$. The filtrate was concentrated under reduced pressure to give a white solid, which was dissolved in $\mathrm{CH}_{2} \mathrm{Cl}_{2}(1.5 \mathrm{~mL})$. TFA $(1.5 \mathrm{~mL})$ was added to the mixture at $0{ }^{\circ} \mathrm{C}$. After stirring for 15 min at room temperature, the mixture was concentrated under reduced pressure to give an oily residue, which was purified by flash chromatography over silica gel with $\mathrm{CHCl}_{3}-\mathrm{MeOH}-28 \%$ $\mathrm{NH}_{4} \mathrm{OH}(95: 4: 1)$ to give 7 as a white solid $(23 \mathrm{mg}, 88 \%$ yield $) ;[\alpha]^{25}+1.48\left(c 0.056, \mathrm{CHCl}_{3}\right) ;{ }^{1} \mathrm{H}$ NMR (500 MHz, $\left.\mathrm{CDCl}_{3}\right) \delta 0.88(\mathrm{t}, J=6.9 \mathrm{~Hz}, 3 \mathrm{H}), 1.20-1.42(\mathrm{~m}, 24 \mathrm{H}), 1.42-1.67(\mathrm{~m}, 2 \mathrm{H}), 2.14$ $2.42(\mathrm{~m}, 2 \mathrm{H}), 3.33(\mathrm{~m}, 1 \mathrm{H}), 3.53-3.57(\mathrm{~m}, 1 \mathrm{H}), 3.57-3.63(\mathrm{~m}, 2 \mathrm{H}), 4.00(\mathrm{dd}, J=9.2,6.3 \mathrm{~Hz}, 1 \mathrm{H})$. Anal. Calcd for $\mathrm{C}_{18} \mathrm{H}_{37} \mathrm{NO}_{2}$ : C, 72.19; H, 12.45; N, 4.68. Found: C, 72.29; H, 12.16; N, 4.61. 
4.1.16. tert-Butyl $[(2 R, 3 S, 4 S)-1,3,4-$ Trihydroxyoctadecan-2-yl]carbamate (21). To a stirred solution of $18(87 \mathrm{mg}, 0.152 \mathrm{mmol})$ in THF $(3.0 \mathrm{~mL})$ was added TBAF $(1.0 \mathrm{M}$ in THF; $304 \mu \mathrm{L}$, $0.304 \mathrm{mmol}$ ) at $0{ }^{\circ} \mathrm{C}$, and the mixture was stirred for $20 \mathrm{~min}$ at room temperature. The mixture was quenched by addition of saturated $\mathrm{NH}_{4} \mathrm{Cl}$ at $0{ }^{\circ} \mathrm{C}$, and concentrated under reduced pressure. The residue was extracted with EtOAc, dried over $\mathrm{MgSO}_{4}$. The filtrate was concentrated under reduced pressure to give an oily residue, which was purified by flash chromatography over silica gel with $n$ hexane-EtOAc (1:1 to $1: 2)$ to give 21 as a white solid (59 mg, $93 \%$ yield); mp $68-70{ }^{\circ} \mathrm{C}$; $[\alpha]^{25}{ }_{\mathrm{D}}^{-}$ $4.33\left(c \mathrm{1.14}, \mathrm{CHCl}_{3}\right) ;{ }^{1} \mathrm{H}$ NMR $\left(500 \mathrm{MHz}, \mathrm{CDCl}_{3}\right) \delta 0.88(\mathrm{t}, J=6.9 \mathrm{~Hz}, 3 \mathrm{H}), 1.20-1.39(\mathrm{~m}, 26 \mathrm{H})$, $1.45(\mathrm{~s}, 9 \mathrm{H}), 2.29(\mathrm{~m}, 1 \mathrm{H}), 2.65(\mathrm{~m}, 1 \mathrm{H}), 2.99(\mathrm{~m}, 1 \mathrm{H}), 3.61-3.68(\mathrm{~m}, 2 \mathrm{H}), 3.69-3.77(\mathrm{~m}, 2 \mathrm{H}), 3.89$ (m, 1H), 5.27 (m, 1H); HRMS (FAB) calcd for $\mathrm{C}_{23} \mathrm{H}_{46} \mathrm{NO}_{5}\left([\mathrm{M}-\mathrm{H}]^{-}\right)$416.3381, found 416.3391 .

\subsubsection{7. tert-Butyl $[(3 R, 4 S, 5 S)-4-H y d r o x y-5$-tetradecyltetrahydrofuran-3-yl]carbamate (22).}

To a stirred mixture of $21(42 \mathrm{mg}, 0.100 \mathrm{mmol})$ and $\mathrm{Et}_{3} \mathrm{~N}(111 \mu \mathrm{L}, 0.800 \mathrm{mmol})$ in $\mathrm{CH}_{2} \mathrm{Cl}_{2}(3.3 \mathrm{~mL})$ were added $\mathrm{TsCl}(76 \mathrm{mg}, 0.400 \mathrm{mmol})$ and $\mathrm{Me}_{3} \mathrm{~N} \cdot \mathrm{HCl}(10 \mathrm{mg}, 0.100 \mathrm{mmol})$ at $-78{ }^{\circ} \mathrm{C}$, and the mixture was stirred for $4 \mathrm{~h}$ at this temperature. The mixture was quenched by addition of EtOH at $0{ }^{\circ} \mathrm{C}$, and concentrated under reduced pressure. The residue was extracted with $\mathrm{Et}_{2} \mathrm{O}$, washed with saturated $\mathrm{NH}_{4} \mathrm{Cl}$ and brine, and dried over $\mathrm{MgSO}_{4}$. The filtrate was concentrated under reduced pressure to give an oily residue, which was dissolved in $\mathrm{MeOH}(3.3 \mathrm{~mL}) . \mathrm{K}_{2} \mathrm{CO}_{3}(41 \mathrm{mg}, 0.300$ mmol) was added to the stirred mixture at $0{ }^{\circ} \mathrm{C}$, and the mixture was stirred for 30 min at room temperature. The mixture was quenched by addition of saturated $\mathrm{NH}_{4} \mathrm{Cl}$, and concentrated under reduced pressure. The residue was extracted with EtOAc, washed with brine, and dried over $\mathrm{MgSO}_{4}$. The filtrate was concentrated under reduced pressure to give an oily residue, which was purified by flash chromatography over silica gel with $n$-hexane-EtOAc (5:1 to 3:1) to give 22 as a white solid (21 mg, 53\% yield); mp $105-107{ }^{\circ} \mathrm{C} ;[\alpha]^{25}{ }_{\mathrm{D}}+26.3\left(c 0.13, \mathrm{CHCl}_{3}\right) ;{ }^{1} \mathrm{H}$ NMR $\left(500 \mathrm{MHz}, \mathrm{CDCl}_{3}\right) \delta$ $0.88(\mathrm{t}, J=6.9 \mathrm{~Hz}, 3 \mathrm{H}), 1.24-1.35(\mathrm{~m}, 24 \mathrm{H}), 1.45(\mathrm{~s}, 9 \mathrm{H}), 1.59-1.66(\mathrm{~m}, 2 \mathrm{H}), 2.27(\mathrm{~m}, 1 \mathrm{H}), 3.44$ 
$(\mathrm{dd}, J=9.7,4.0,1 \mathrm{H}), 3.81(\mathrm{~m}, 1 \mathrm{H}), 4.00(\mathrm{~m}, 1 \mathrm{H}), 4.07(\mathrm{~m}, 1 \mathrm{H}), 4.24(\mathrm{~m}, 1 \mathrm{H}), 4.62(\mathrm{~m}, 1 \mathrm{H})$; HRMS (FAB) calcd for $\mathrm{C}_{23} \mathrm{H}_{44} \mathrm{NO}_{5}\left([\mathrm{M}-\mathrm{H}]^{-}\right)$: 398.3276 , found 398.3275 .

4.1.18. (2S,3S,4R)-4-Amino-2-tetradecyltetrahydrofuran-3-ol (8). By a procedure identical with that described for synthesis of $\mathbf{6}$ from 15, $22(30 \mathrm{mg}, 0.075 \mathrm{mmol})$ was converted into 8 as a white solid (22 mg, 98\%); mp 80-82 ${ }^{\circ} \mathrm{C}$; $[\alpha]^{25}{ }_{\mathrm{D}}+2.33\left(c 0.20, \mathrm{CHCl}_{3}\right) ;{ }^{1} \mathrm{H} \mathrm{NMR}\left(500 \mathrm{MHz}, \mathrm{CDCl}_{3}\right)$ $\delta 0.88(\mathrm{t}, J=6.9 \mathrm{~Hz}, 3 \mathrm{H}), 1.21-1.40(\mathrm{~m}, 24 \mathrm{H}), 1.40-1.69(\mathrm{~m}, 5 \mathrm{H}), 3.39(\mathrm{dd}, J=9.7,3.4 \mathrm{~Hz}, 1 \mathrm{H})$, $3.47(\mathrm{~m}, 1 \mathrm{H}), 3.81(\mathrm{~m}, 1 \mathrm{H}), 3.90(\mathrm{~m}, 1 \mathrm{H}), 4.21(\mathrm{dd}, J=9.7,6.3 \mathrm{~Hz}, 1 \mathrm{H})$. Anal. Calcd for $\mathrm{C}_{18} \mathrm{H}_{37} \mathrm{NO}_{2} \cdot 0.25 \mathrm{H}_{2} \mathrm{O}: \mathrm{C}, 71.12 ; \mathrm{H}, 12.43 ; \mathrm{N}, 4.61$. Found: $\mathrm{C}, 71.19 ; \mathrm{H}, 12.45 ; \mathrm{N}, 4.40$.

\subsection{Sphingosine Kinase Assay}

SphK inhibitory activities were evaluated by the off-chip mobility shift assay by the QuickScout ${ }^{\circledR}$ service from Carna Bioscience (Kobe, Japan). SphK1(1-384) and SphK2(1-618) were expressed as N-terminal GST-fusion proteins using a baculovirus expression system. They were purified using glutathione sepharose chromatography. Each chemical in DMSO at different concentrations was diluted fourfold with reaction buffer [20 mM HEPES (pH 7.5), 0.01\% Triton X-100, 2 mM DTT]. For SphK reactions, a combination of the compound, $1 \mu \mathrm{M}$ Sph, $5 \mathrm{mM} \mathrm{MgCl} 2$, ATP $(25 \mu \mathrm{M}$ for SphK1; $600 \mu \mathrm{M}$ for SphK2) in reaction buffer $(20 \mu \mathrm{L})$ were incubated with each SphK in 384-well plates at room temperature for $1 \mathrm{~h}(n=4)$. The reaction was terminated by addition of $60 \mu \mathrm{L}$ of termination buffer (Carna Biosciences). Substrate and product were separated by electrophoretic means using the LabChip3000 system. The kinase reaction was evaluated by the product ratio, which was calculated from the peak heights of the substrate $(\mathrm{S})$ and product $(\mathrm{P}):[\mathrm{P} /(\mathrm{P}+\mathrm{S})]$. Inhibition data were calculated by comparing with no-enzyme controls for $100 \%$ inhibition and noinhibitor reactions for $0 \%$ inhibition. $\mathrm{IC}_{50}$ values were calculated using GraphPad Prism 4 software (GraphPad Software, Incorporated, La Jolla, CA, USA). 


\subsection{Protein Kinase C (PKC) Assay}

PKC inhibitory activities were evaluated using the off-chip mobility shift assay by the QuickScout $^{\circledR}$ service from Carna Bioscience (Kobe, Japan). N-terminal GST-fusion protein were employed for the assays: PKC $\alpha(1-672), \operatorname{PKC} \beta 1(1-671), \operatorname{PKC} \beta 2(1-673), \operatorname{PKC} \gamma(1-697), \operatorname{PKC} \delta(1-$ 676), $\operatorname{PKC} \varepsilon(1-737), \operatorname{PKC} \zeta(1-592), \operatorname{PKC} \eta(1-683), \operatorname{PKC} \theta(1-706)$, and $\operatorname{PKCl}(1-587)$. These were expressed using the baculovirus expression system and purified by glutathione sepharose chromatography. Each chemical in DMSO at different concentrations was diluted fourfold with reaction buffer [20 mM HEPES ( $\mathrm{pH} 7.5$ ), 0.01\% Triton X-100, $2 \mathrm{mM}$ DTT]. For the kinase reactions except for $\mathrm{PKC} \zeta$ and $\mathrm{PKCl}$, phosphatidylserine $(50 \mu \mathrm{g} / \mathrm{mL})$ and diacyl glycerol $(5 \mu \mathrm{g} / \mathrm{mL})$ were added. A combination of the compound, $1 \mu \mathrm{M}$ PKC $\theta$ substrate (N-FL), ATP (25 $\mu \mathrm{M}$ for $\mathrm{PKC} \alpha / \beta 1 / \gamma / \eta / \theta / 1 ; 10 \mu \mathrm{M}$ for $\mathrm{PKC} \beta 2 / \delta / \varepsilon ; 5 \mu \mathrm{M}$ for $\mathrm{PKC} \zeta$ ), $5 \mathrm{mM} \mathrm{MgCl}_{2}$, and $50 \mu \mathrm{M} \mathrm{CaCl}_{2}$ (for $\mathrm{PKC} \alpha / \beta 1 / \beta 2 / \gamma)$ in reaction buffer $(20 \mu \mathrm{L})$ were incubated with each $\mathrm{PKC}$ in 384 -well plates at room temperature for $1 \mathrm{~h}(n=2)$. The reaction was terminated by addition of $60 \mu \mathrm{L}$ of termination buffer (Carna Biosciences). Substrate and product were separated by electrophoretic means using the LabChip3000 system. The kinase reaction was evaluated by the product ratio, which was calculated from the peak heights of the substrate $(\mathrm{S})$ and product $(\mathrm{P})$ peptides: $[\mathrm{P} /(\mathrm{P}+\mathrm{S})]$. Inhibition data were calculated by comparing with no-enzyme controls for $100 \%$ inhibition and no-inhibitor reactions for $0 \%$ inhibition.

\section{Acknowledgements}

This work was supported by Grants-in-Aid for Scientific Research from the Ministry of Education, Culture, Sports, Science and Technology of Japan, and Targeted Proteins Research Program. Y.Y. and S.I. are grateful for Research Fellowships from the Japan Society for the Promotion of Science (JSPS) for Young Scientists. 


\section{Supplementary data}

Supplementary data associated with this article can be found, in the online version, at doi:10.1016/j.bmc.2011.07.061.

\section{References and footnotes}

1 For a review, see: Fyrst, H.; Saba, J. D. Nat. Chem. Biol. 2010, 6, 489.

2 Hannun, Y. A. J. Biol. Chem. 1994, 269, 3125.

3 Spiegel, S.; Milstien, S. J. Biol. Chem. 2002, 277, 25851.

4 Takabe, K.; Paugh, S. W.; Milstien, S.; Spiegel, S. Pharmacol. Rev. 2008, 60, 181.

5 Pyne, N. J.; Pyne, S. Nat. Rev. Cancer 2010, 10, 489.

6 Kohama, T.; Olivera, A.; Edsall, L.; Negiec, M. M.; Dickson, R.; Spiegel, S. J. Biol. Chem. 1998, 273, 23722.

7 Liu, H.; Sugiura, M.; Nava, V. E.; Edsall, L. C.; Kono, K.; Poulton, S.; Milstien, S.; Kohama, T.; Spiegel, S. J. Biol. Chem. 2000, 275, 19513.

8 Xia, P.; Gamble J. R.; Wang, L.; Pitson, S. M.; Moretti, P. A.; Wattenberg, B. W.; D'Andrea, R. J.; Vadas, M. A. Curr. Biol. 2000, 10, 1527.

9 Pchejetski, D.; Golzio, M.; Bonhoure, E.; Calvet, C.; Doumerc, N.; Garcia, V.; Mazerolles, C.; Rischmann, P.; Teissié, J.; Malavaud, B.; Cuvillier, O. Cancer Res. 2005, 65, 11667.

10 Sauer, L.; Nunes, J.; Salunkhe, V.; Skalska, L.; Kohama, T.; Cuvillier, O.; Waxman, J.; Pchejetski, D. Int. J. Cancer. 2009, 125, 2728.

11 Liu, H.; Toman, R. E.; Goparaju, S. K.; Maceyka, M.; Nava, V. E.; Sankala, H.; Payne, S. G.; Bektas, M.; Ishii, I.; Chun, J.; Milstien, S.; Spiegel, S. J. Biol. Chem. 2003, 278, 40330.

12 Fitzpatrick L. R.; Green, C.; Maines, L. W.; Smith, C. D. Pharmacology 2011, 87, 135.

13 For a review, see: Pitman M. R.; Pitson S. M. Curr. Cancer Drug Targets 2010, 10, 354. 
14 Kuroda, I.; Musman, M.; Ohtani, I.; Ichiba, T.; Tanaka, J.; Garcia-Gravalos, D.; Higa, T. J. Nat. Prod. 2002, 65, 1505.

15 Canals, D.; Mormeneo, D.; Fabriàs, G.; Llebaria, A.; Casas, J.; Delgado, A. Bioorg. Med. Chem. 2009, 17, 235.

16 Jayachitra, G.; Sudhakar, N.; Anchoori, R. K.; Rao, V.; Roy, S.; Banerjee, R. Synthesis 2010, 115.

17 Salma, Y.; Lafont, E.; Therville, N.; Carpentier, S.; Bonnafe, M. J.; Levade, T.; Génisson, Y.; Andrieu-Abadie, N. Biochem. Pharmacol. 2009, 78, 477.

18 Yoshimitsu, Y.; Inuki, S.; Oishi, S.; Fujii, N.; Ohno, H. J. Org. Chem. 2010, 75, 3843.

19 Azuma, H.; Tamagaki, S.; Ogino, K. J. Org. Chem. 2000, 65, 3538.

20 van den Berg, R.; Boltje, T.; Verhagen, C.; Litjens, R.; Vander Marel, G.; Overkleeft, H. J. Org. Chem. 2006, 71, 836.

21 Perrin, D.; Frémaux, C.; Scheer, A. J. Biomol. Screen. 2006, 11, 359.

22 Yatomi, Y.; Ruan, F.; Megidish, T.; Toyokuni, T.; Hakomori, S.; Igarashi, Y. Biochemistry 1996, 35, 626.

23 Buehrer, B. M,; Bell, R. M. J. Biol. Chem. 1992, 267, 3154.

24 Recently, anticancer activity of a series of 1-deoxysphingolipid stereisomers was reported, see: Dougherty, A. M.; McDonald, F. E.; Liotta, D. C.; Moody, S. J.; Pallas, D. C.; Pack, C. D.; Merrill, A. H. Org. Lett. 2006, 8, 649.

25 Garnier-Amblard, E. C.; Mays, S. G.; Arrendale, R. F.; Baillie, M. T.; Bushnev, A. S.; Culver, D. G.; Evers, T. J.; Holt, J. J.; Howard, R. B.; Liebeskind, L. S.; Menaldino, D. S.; Natchus, M. G.; Petros, J. A.; Ramaraju, H.; Reddy, G. P.; Liotta, D. C. ACS Med. Chem. Lett. 2011, 2, 438.

26 Wong, L.; Tan, S. S. L.; Lam, Y.; Melendez, A. J. J. Med. Chem. 2009, 52, 3618.

27 Kono, K.; Tanaka, M.; Ogita, T.; Kohama, T. J. Antibiot. 2000, 53, 759. 
28 Khan, W. A.; Dobrowsky, R.; Touny, S. E.; Hannun, Y. A. Biochem. Biophys. Res. Commun. 1990, 172, 683.

29 Kimura, S.; Kawa, S.; Ruan, F.; Nisar, M.; Sadahira, Y.; Hakomori, S.; Igarashi, Y. Biochem. Pharmacol. 1992, 44, 1585.

30 For a review, see: Rosse, C.; Linch, M.; Kermorgant, S.; Cameron, A. J. M.; Boeckeler, K.; Parker, P. J. Nat. Rev. Mol. Cell. Biol. 2010, 11, 103.

31 Fields, A. P.; Regala, R. P. Protein kinase C1: Pharmacol. Res. 2007, 55, 487.

32 Irie, K.; Oie, K.; Nakahara, A.; Yanai, Y.; Ohigashi, H.; Wender, P. A.; Fukuda, H.; Konishi, H.; Kikkawa, U. J. Am. Chem. Soc. 1998, 120, 9159.

33 Mathews, T. P.; Kennedy, A. J.; Kharel, Y.; Kennedy, P. C.; Nicoara, O.; Sunkara, M.; Morris, A. J.; Wamhoff, B. R.; Lynch, K.R.; Macdonald, T. L. J. Med. Chem. 2010, 53, 2766.

34 van Blitterswijk, W. J. Biochem. J. 1998, 331, 677.

35 Although we assumed that pachastrissamines could mimic the structure of Cer, the potential inhibition of atypical PKCs by binding to the catalytic domain cannot be ruled out. 
Table 1. Inhibitory activity of pachastrissamine and its stereoisomers against sphingosine kinases

\begin{tabular}{lcc}
\hline & \multicolumn{2}{c}{$\mathrm{IC}_{50}{ }^{a}$} \\
\cline { 2 - 3 } compound & $\mathrm{SphK} 1$ & $\mathrm{SphK} 2$ \\
\hline $\mathbf{2}$ (pachastrissamine) & 4.6 & 6.6 \\
$\mathbf{3}$ & 3.9 & 15.8 \\
$\mathbf{4}$ & 2.1 & 6.1 \\
$\mathbf{5}$ & 3.0 & 2.2 \\
$\mathbf{6}$ & 2.7 & 10.5 \\
$\mathbf{7}$ & 2.1 & 6.2 \\
$\mathbf{8}$ & 0.59 & 1.8 \\
$\mathrm{DMS}^{b}$ & 0.94 & 0.48 \\
& 2.8 & 13.7
\end{tabular}

${ }^{a} \mathrm{IC}_{50}$ values are the concentrations for $50 \%$ inhibition of the sphingosine phosphorylation by SphK1 or SphK2. The data were derived from the dose-response curves generated from triplicate data points. ${ }^{b} N, N$-dimethylsphingosine.

Figure 1. Metabolism of sphingolipids in mammalian cells.

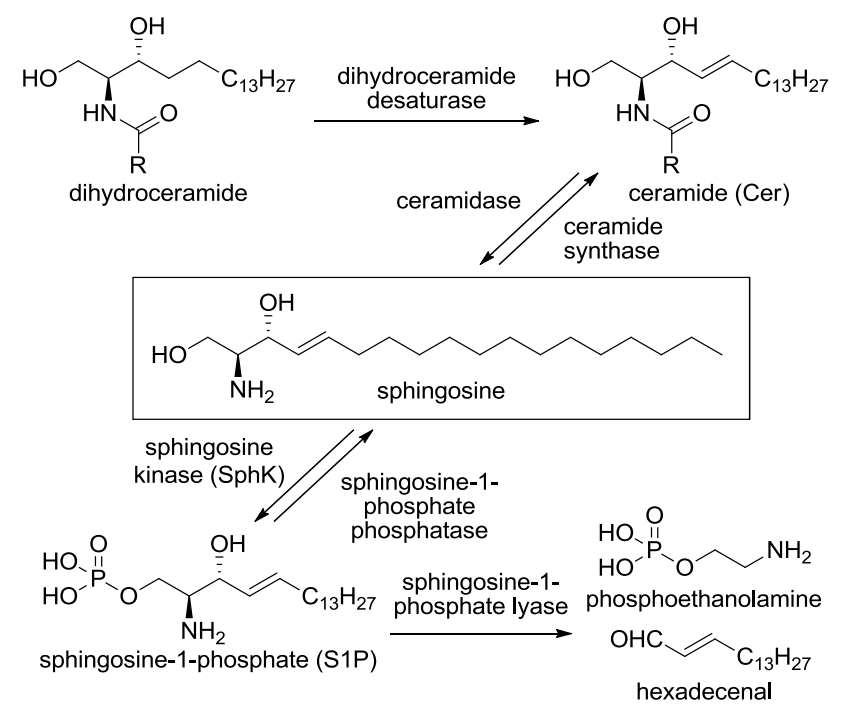


Figure 2. Structures of pachastrissamine stereoisomers.

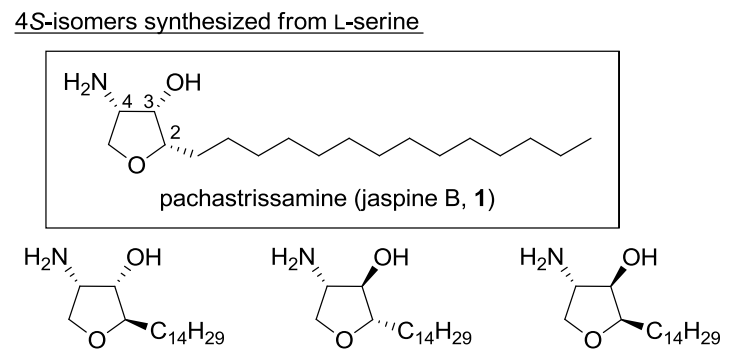

$(2 R, 3 S, 4 S)$-isomer (2) $(2 S, 3 R, 4 S)$-isomer $(3)(2 R, 3 R, 4 S)$-isomer (4)

$\underline{4 R \text {-isomers synthesized from } D \text {-serine }}$
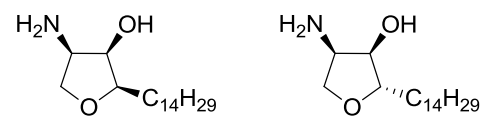

$(2 R, 3 R, 4 R)$-isomer (5) $\quad(2 S, 3 R, 4 R)$-isomer (6)
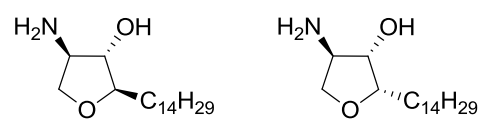

$(2 R, 3 S, 4 R)$-isomer $(7) \quad(2 S, 3 S, 4 R)$-isomer (8)

Figure 3. Inhibitory activity of pachastrissamine stereoisomers against $\mathrm{PKC \zeta}$ (A) and $\mathrm{PKC \imath}(\mathrm{B})$. Values are reported as percentages of maximum activity of PKCs from duplicate data points.
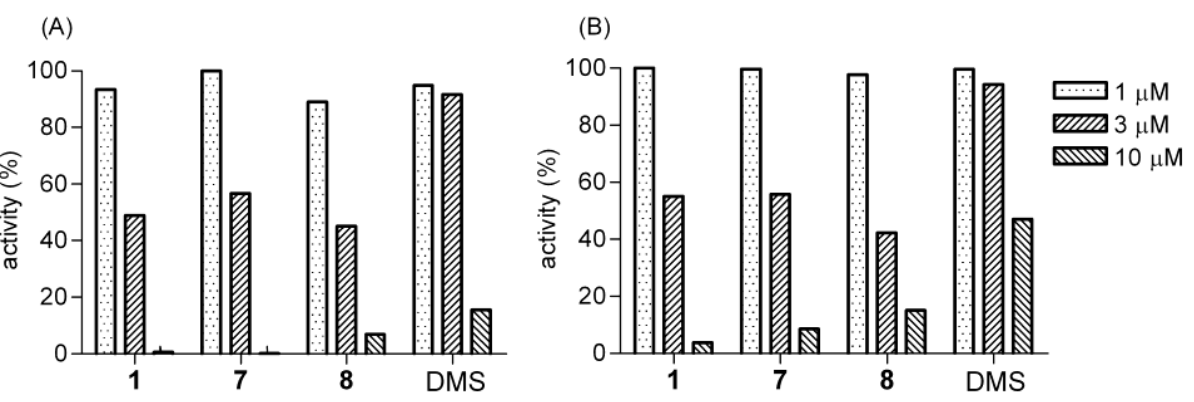
Scheme 1. Stereoselective synthesis of pachastrissamine stereoisomers 5-8.

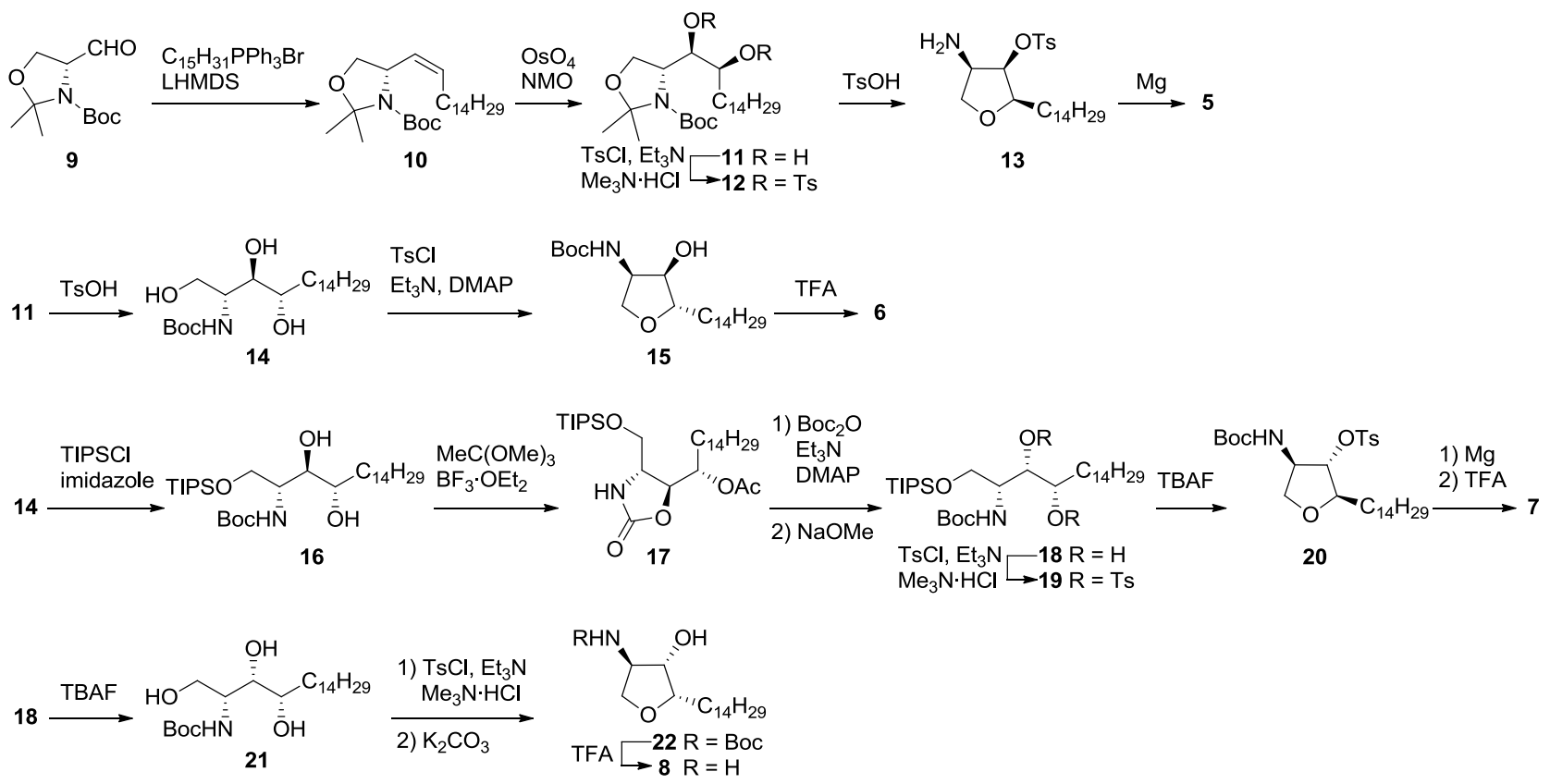

\section{Graphical Table of Contents}

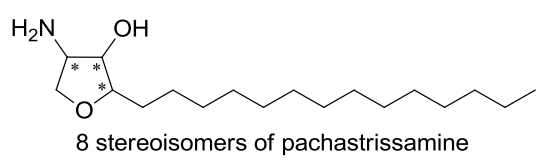

